See Article page 636.

\section{Commentary: Silent brain lesions after coronary artery bypass grafting - Reexamining the sound of silence}

\author{
Andrew M. Vekstein, MD, ${ }^{\mathrm{a}}$ and \\ Shu S. Lin, MD, PhD ${ }^{\mathrm{a}, \mathrm{b}, \mathrm{c}}$
}

Stroke remains one of the most feared complications after coronary artery bypass grafting (CABG) and is associated with as much as 10 times greater in-hospital mortality. ${ }^{1}$ Although large series have investigated clinical cerebrovascular events and identified risk factors, such as history of cerebrovascular disease or prolonged cardiopulmonary bypass time, subclinical neurologic events and their longterm impact remain poorly understood. ${ }^{2,3}$ These so-called silent infarcts refer to new brain lesions on postoperative imaging in patients without any correlating focal neurologic findings. Many postoperative patients demonstrate a more subtle neurocognitive decline, whether transient or persistent, which has been hypothesized to be related to these "silent" lesions; however, previous studies have not found a relationship between imaging findings and neurocognitive decline. ${ }^{4}$ A significant limitation of previous studies on this topic has been a lack of both preoperative and postoperative imaging to compare lesions and assess their significance better in the context of existing cerebrovascular disease. Such imaging is critical, because the etiology of post-CABG stroke is thought to be diverse, including air embolism, aortic atherosclerotic disease, perioperative hypotensive periods, and existing disease of the carotid or cerebral vessels. ${ }^{5}$ A 2011 study by Lee and associates ${ }^{6}$ used preoperative magnetic resonance imaging (MRI) in 1367 patients to score cerebral atherosclerosis, which correlated

\footnotetext{
From the a Division of Thoracic and Cardiovascular Surgery, Department of Surgery, Duke University Health System, Durham, NC; Departments of ${ }^{\mathrm{b}}$ Immunology and ${ }^{c}$ Pathology, Duke University School of Medicine, Durham, NC.

Disclosures: Authors have nothing to disclose with regard to commercial support.

Received for publication Oct 23, 2019; revisions received Oct 23, 2019; accepted for publication Oct 23, 2019; available ahead of print Nov 15, 2019.

Address for reprints: Shu S. Lin, MD, PhD, Division of Thoracic and Cardiovascular Surgery, Department of Surgery, Duke University Medical Center, Box 3392 Durham, NC 27710 (E-mail: shu.lin@ duke.edu).

J Thorac Cardiovasc Surg 2021;161:649-50 $0022-5223 / \$ 36.00$

Copyright (c) 2020 Published by Elsevier Inc. on behalf of The American Association for Thoracic Surgery

https://doi.org/10.1016/j.jtcvs.2019.10.134
}

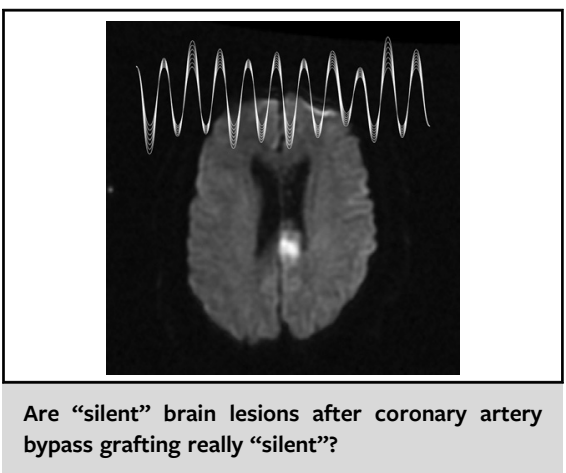

\author{
CENTRAL MESSAGE \\ With MRI before and after CABG, \\ Tachibana and colleagues more \\ accurately characterized new \\ "silent" brain lesions and found \\ that multiple and large lesions \\ are associated with cognitive \\ dysfunction.
}

with postoperative stroke. Imaging was not, unfortunately, obtained to assess for silent findings. ${ }^{6}$ Conversely, many studies have used postoperative MRI, with focus on diffusion-weighted imaging to identify silent injuries, but these studies lack a preoperative imaging correlate. ${ }^{4}$

In this issue of the Journal, Tachibana and colleagues ${ }^{7}$ examined 104 patients who underwent elective, isolated, first-time CABG during a 2-year period (2016-2018) and used both preoperative and postoperative MRI to detect new brain lesions. Tachibana and colleagues ${ }^{7}$ divided the patients into 2 groups (lesions vs no lesions) and looked at the different types of surgical approaches that were used, as well as analyzing the postoperative outcomes, including physical and cognitive functions, in each group. Overall, they found new brain lesions in $20.1 \%$ of the patients. Although the percentages of patients who underwent on-pump (as opposed to off-pump) procedures and those who had aortic crossclamping (as opposed to aorta notouch technique) were higher in the positive lesion group, those who underwent off-pump and aorta no-touch CABG procedure still had a significant incidence of MRIdetected brain lesions. In addition, the Katz activities of daily living index was lower in patients with these lesions, although no significant differences were found in changes of physical or cognitive functions. 
Tachibana and colleagues ${ }^{7}$ are to be commended for including patients who underwent off-pump CABG and on-pump CABG, subsets of whom underwent aortic crossclamping versus side clamping versus beating-heart operations. Their team was thus able to comment on the spectrum of approaches to coronary surgery, each of which presents a slightly different set of risk factors for stroke, including manipulation of the aorta, sutured versus device-based proximal anastomoses, and cardiopulmonary bypass itself. Tachibana and colleagues ${ }^{7}$ present significantly higher incidences of silent brain lesions in on-pump CABG compared to off-pump CABG and in crossclamp or side-clamp procedures relative to beating-heart operations. Long-term conclusions from these data are limited, however, by the number of patients and the lack of matched comparisons among these groups. Patient-specific factors contribute to the decision to use cardiopulmonary bypass or not and therefore may confound broader conclusions about CABG approach and incidence of silent brain lesions.

Still, in contrast to most other articles that have been published on this topic, there are 3 aspects of this study that are quite refreshing. First, the most impressive accomplishment is that both preoperative and postoperative MRIs were performed for each patient. The data reported in this study should therefore present a more accurate picture of the incidence of these lesions after CABG. Second, the design of this research project is relatively novel, in that the data analysis was performed by first dividing the patients into those with and without the brain lesions and then examining for the factors associated with them. Typically, the patients would be first grouped into on-pump versus off-pump $\mathrm{CABG}$, for example, and then evaluated for how many of those had brain lesions and how many did not. This alternative method of presenting the data may be somewhat confusing for some readers at first, but it is certainly different from most other studies. Third, perhaps the most novel aspect of this article is the correlation between the number and size of the lesions and the development of pos-operative cognitive dysfunction, although the exact cause-and-effect relationship cannot be demonstrated merely with the given data. Still, this is valuable information, which would certainly contribute meaningfully to the knowledge base in the important area of neurocognitive complications related to cardiac surgery.

In summary, amid a multitude of papers about adverse effects of CABG on the brain, Tachibana and colleagues ${ }^{7}$ report the first systematic study in which both pre-CABG and post-CABG brain MRIs were performed in each patient, thus allowing them to distinguish new lesions from preexisting lesions confidently. Although the sample size of the study is relatively small, Tachibana and colleagues ${ }^{7}$ have also taken the first steps toward more accurately correlating the number and the size of these new lesions with some of the known adverse neurocognitive consequences of CABG. The implication here is that some of the adverse effects on the brain after heart surgery, such as "pump head" or other even more subtle symptoms and signs, may be associated with these larger or more numerous "silent" brain lesions. This article thus prompts us to reexamine the idea that these "silent" lesions are indeed quiet, or that they are making some sound, no matter how faint it may be. The next move in this line of research would be to verify the findings in a larger study with longer-term follow-up, which would help to determine whether there is any value to formulating strategies to try to prevent the formation of these lesions or whether it is even worth diagnosing them.

\section{References}

1. Filsoufi F, Rahmanian PB, Castillo JG, Bronster D, Adams DH. Incidence, topography, predictors and long-term survival after stroke in patients undergoing coronary artery bypass grafting. Ann Thorac Surg. 2008;85:862-70.

2. Bucerius J, Gummert JF, Borger MA, Walther T, Doll N, Onnasch JF, et al. Stroke after cardiac surgery: a risk factor analysis of 16,184 consecutive adult patients. Ann Thorac Surg. 2003;75:472-8.

3. Tarakji KG, Sabik JF III, Bhudia SK, Batizy LH, Blackstone EH. Temporal onset, risk factors, and outcomes associated with stroke after coronary artery bypass grafting. JAMA. 2011;305:381-90.

4. Knipp SC, Matatko N, Wilhelm H, Schlamann M, Massoudy P, Forsting M, et al. Evaluation of brain injury after coronary artery bypass grafting. A prospective study using neuropsychological assessment and diffusion-weighted magnetic resonance imaging. Eur J Cardiothorac Surg. 2004;25:791-800.

5. Sun X, Lindsay J, Monsein LH, Hill PC, Corso PJ. Silent brain injury after cardiac surgery: a review: cognitive dysfunction and magnetic resonance imaging diffusion-weighted imaging findings. J Am Coll Cardiol. 2012;60:791-7.

6. Lee EJ, Choi KH, Ryu JS, Jeon SB, Lee SW, Park SW, et al. Stroke risk after coronary artery bypass graft surgery and extent of cerebral artery atherosclerosis. J Am Coll Cardiol. 2011;57:1811-8.

7. Tachibana H, Hiraoka A, Saito K, Naito Y, Chikazawa G, Tamura K, et al. Incidence and impact of silent brain lesions after coronary artery bypass grafting. J Thorac Cardiovasc Surg. 2021;161:636-44. 